\title{
Insomnia in hospitalized psychiatric patients: prevalence and associated factors
}

This article was published in the following Dove Press journal:

Neuropsychiatric Disease and Treatment

\author{
Farid Talih' \\ Jean Ajaltouni' \\ Hiba Ghandour ${ }^{2}$ \\ Ahmad Subhi \\ Abu-Mohammad ${ }^{2}$ \\ Firas Kobeissy ${ }^{2,3}$ \\ 'Department of Psychiatry, American \\ University of Beirut Medical Center, \\ Beirut, Lebanon; ${ }^{2}$ Faculty of Medicine, \\ American University of Beirut, \\ Beirut, Lebanon; ${ }^{3}$ Department of \\ Biochemistry and Molecular Genetics, \\ Faculty of Medicine, American \\ University of Beirut, Beirut, Lebanon
}

Correspondence: Farid Talih

American University of Beirut,

3 Dag Hammarskjold Plaza, 8th Floor,

New York, NY I00 I7-2303, USA

Email ft10@aub.edu.lb

Firas Kobeissy

Department of Biochemistry and

Molecular Genetics, American

University of Beirut, P.O. Box II-0236,

Beirut I 107-2020, Lebanon

Email fk02@aub.edu.lb
Objectives: To quantify and describe the prevalence of insomnia in hospitalized psychiatric patients and to investigate the associations between insomnia and demographic and clinical factors in hospitalized psychiatric patients.

Methods: The participants included 203 individuals hospitalized for psychiatric treatment at an academic medical center. Demographic information, psychiatric diagnoses, current psychotropic medication use, and history of substance use were collected. Insomnia screening was performed using the Insomnia Severity Index. Depressive and anxiety symptoms were also evaluated using the Generalized Anxiety Disorder questionnaire and the Patient Health Questionnaire. Restless legs syndrome (RLS) symptoms were evaluated using the Restless Legs Syndrome Rating Scale (RLSRS). Statistical analysis was conducted to detect the prevalence of insomnia among the participants and to examine possible associations among psychiatric disorders, psychotropic medications, and RLS.

Results: Out of the 203 participants that completed the survey, 67.4\% were found to have insomnia and $14.3 \%$ were found to have RLS. The severity of insomnia was found to be associated with the presence of RLS, depressive and anxious symptomatology, suicidal ideation, use of selective serotonin reuptake inhibitors, and use of benzodiazepines.

Keywords: insomnia, depression, anxiety, restless legs syndrome

\section{Introduction}

Sleep can influence physical and mental health. ${ }^{1}$ Sleep disturbances are common ${ }^{2}$ and have various etiologies. ${ }^{3}$ The overlap between psychiatric and sleep disorders has been well established in the literature. ${ }^{4,5}$ Recently, sleep disorders including insomnia are being considered as separate entities that can co-occur with other disorders, including psychiatric disorders. Therefore, the Diagnostic and Statistical Manual 5th edition criteria for psychiatric disorders now include sleep disturbances as a comorbidity in conditions such as depression, mania, and posttraumatic stress disorder. ${ }^{6,7}$ Psychotropic medications may have a positive effect on sleep; some enhance sleep architecture, ${ }^{8}$ but others can have negative effects. Some antipsychotics have been shown to improve sleep, but frequently cause daytime somnolence. Antidepressants may improve daytime alertness but many worsen sleep architecture. ${ }^{8}$

Substance abuse has a bidirectional relationship with sleep and psychiatric disorders. Frequently, substance abuse develops due to attempts to self-medicate sleep disorders. ${ }^{9}$ Stimulants, for example, can cause insomnia, while sedative abuse may cause excessive daytime sleepiness.

Insomnia has a complex relationship with many mental health disorders. ${ }^{10}$ Sleep deprivation can trigger mania in bipolar patients or increase irritability and fatigue in depressed patients. ${ }^{7}$ Insomniacs may abuse sedatives such as alcohol or cannabis, 
which can lead to addiction or may exacerbate existing psychiatric disorders. Insomnia can also be secondary to psychiatric disorders such as anxiety, or a reduced need for sleep due to mania, or as a result of psychotic phenomenon such as paranoia. ${ }^{7}$ Other sleep disorders, such as restless legs syndrome (RLS) or delayed sleep phase syndrome, may also present as insomnia. To the best of our knowledge, little data exists on insomnia in hospitalized psychiatric patients.

This study aimed to determine the prevalence of insomnia in a sample of hospitalized psychiatric patients with severe mental illness. We hypothesized that there will be a higher prevalence of insomnia among the psychiatric patients when compared to the general population. Additionally, we investigated factors associated with insomnia such as psychiatric diagnoses, depressive and anxiety symptomatology, RLS, and psychotropic medication use.

\section{Methods}

This was a questionnaire-based survey approved by the institutional review board of the American University of Beirut. The study was conducted at the American University of Beirut Medical Center inpatient psychiatric unit. Following institutional review board approval, participant recruitment began. Participants in this study were individuals hospitalized at the inpatient psychiatry unit at the American University of Beirut Medical Center. All patients presenting to the psychiatric unit were asked to participate. The study began in 2014 and concluded in 2017. The purpose of this research project, its risks, and benefits were explained to the participants before obtaining written informed consent. After written informed consent was obtained, participants were asked to complete our survey. Exclusion criteria included being younger than 18 years of age or having a significant cognitive impairment that would prevent the participant from completing the questionnaire. Impairment was determined by the treating psychiatrist and included advanced dementia, severe agitation, and profound developmental delay. The survey included basic demographic and medical information. The questionnaire recorded admitting psychiatric diagnoses, use of substances (alcohol, drugs, caffeine, and nicotine), and currently prescribed medications. The Patient Health Questionnaire (PHQ-9) was used to evaluate depressive symptomatology. It is a nine-item survey for depression validated in Arabic speakers. ${ }^{11,12}$ PHQ scores $\geq 10$ have a sensitivity and specificity of $93 \%$ and $88 \%$, respectively, when screening for depression. ${ }^{11}$ Suicidal ideation was assessed using the ninth item of the PHQ questionnaire which states: "Over the last 2 weeks, how often have you been bothered by thoughts that you would be better off dead or of hurting yourself in some way?"

The Generalized Anxiety Disorder 7 (GAD-7) scale is a seven-item screening tool for anxiety. Using the cutoff score of $\geq 10$, GAD has a sensitivity of $89 \%$ and a specificity of $82 \%$ when screening for anxiety symptoms. ${ }^{13}$ The GAD has been validated in Arabic-speaking populations. ${ }^{12}$

The Insomnia Severity Index (ISI), a seven-item questionnaire, was used to assess for insomnia. ${ }^{14}$ The ISI stratifies insomnia as: none, mild, moderate, and severe. ISI scores are interpreted as follows; 0-7: no insomnia; 8-14: mild insomnia; 15-21: moderate insomnia; 22-28: severe insomnia. The ISI has been shown to have an adequate concurrent validity when compared to sleep diaries and to be sensitive in detecting insomnia. ${ }^{14}$ The ISI is validated in Arabic-speaking populations. ${ }^{15}$

We also examined the prevalence of RLS in our sample using the Restless Legs Syndrome Rating Scale (RLSRS). This validated scale measures RLS symptomatology using a ten-item questionnaire. The RLSRS stratifies symptoms of RLS as mild, moderate, or severe. ${ }^{16}$ Each item is rated from 0-4; with 4 indicating very severe discomfort. RLSRS scores are interpreted as follows; mild: 1-10; moderate: 11-20; severe: 21-30; and very severe: 31-40. The RLSRS has been adapted from the clinician-administered version and has been shown to be valid and reliable in detecting clinically significant RLS. ${ }^{17}$ The RLSRS is validated in Arabic and Arabic-speaking populations. ${ }^{15}$

Collected data were entered into a database and statistically analyzed using Statistical Package for the Social Sciences (SPSS, Chicago, IL, USA) software version 23. We first examined the prevalence of insomnia. Subsequently, we examined demographic factors that might be associated with the severity of insomnia, as well as depressive symptoms, anxiety symptoms, suicidal ideation, RLS, and psychotropic medication use. These variables were studied using the crosstabs measure and Pearson's chi-square tests. Descriptive statistics were performed regarding the prevalence of insomnia based on the total score of each ISI survey.

\section{Results}

Among the 203 participants that completed the survey, the following were the admitting diagnoses: $44.3 \%$ were diagnosed with depression, $15.8 \%$ with substance use disorders, $14.8 \%$ with bipolar disorder, and $12.8 \%$ with psychotic disorders including schizophrenia and schizoaffective disorder (Table 1). In our sample, $40.9 \%$ admitted to napping during the day, $22.7 \%$ reported taking over the 
Table I Patient characteristics stratified by presence or absence of insomnia

\begin{tabular}{|c|c|c|c|}
\hline Patient characteristics & $\begin{array}{l}\text { Patients with } \\
\text { insomnia (\%) } N=137\end{array}$ & $\begin{array}{l}\text { Patients with no } \\
\text { insomnia (\%) } N=66\end{array}$ & $p$-value \\
\hline \multicolumn{4}{|l|}{ Sex } \\
\hline Male & $57(41.30 \%)$ & $34(47.96 \%)$ & 0.24 \\
\hline Female & $79(57.66 \%)$ & $32(52.03 \%)$ & \\
\hline \multicolumn{4}{|l|}{ Age (years) } \\
\hline$<55$ & $13 \mid(95.62 \%)$ & $57(86.34 \%)$ & 0.32 \\
\hline$>55$ & $6(2.5 \%)$ & $9(10.56 \%)$ & \\
\hline \multicolumn{4}{|l|}{ Sleeping hours ${ }^{\mathrm{a}}$} \\
\hline$<7$ hours & $76(55.47 \%)$ & 21 (3I.8I\%) & $<0.001$ \\
\hline$>7$ hours & $6 \mathrm{I}(44.52 \%)$ & $45(68.18 \%)$ & \\
\hline \multicolumn{4}{|l|}{ Diagnosis } \\
\hline Depression & 67 (48.9\%) & $23(34.84 \%)$ & 0.30 \\
\hline Schizophrenia/schizoaffective disorder & $13(9.48 \%)$ & $13(19.69 \%)$ & \\
\hline Bipolar & $22(16.05 \%)$ & $8(12.12 \%)$ & \\
\hline Anxiety disorder & $15(10.94 \%)$ & $8(12.12 \%)$ & \\
\hline Substance abuse & $20(14.59 \%)$ & $12(18.18 \%)$ & \\
\hline Eating disorder & $0(0.00 \%)$ & I (I.5I\%) & \\
\hline \multicolumn{4}{|l|}{ Depressive symptoms ${ }^{a}$} \\
\hline None & $17(12.40 \%)$ & $19(28.78 \%)$ & $<0.001$ \\
\hline Mild to moderate & $25(18.24 \%)$ & $22(33.33 \%)$ & \\
\hline Severe & $95(69.34 \%)$ & $25(37.87 \%)$ & \\
\hline \multicolumn{4}{|l|}{ Suicidal ideation ${ }^{\mathrm{a}}$} \\
\hline Yes & $80(58.39 \%)$ & $30(45.45 \%)$ & 0.03 \\
\hline No & $57(41.60 \%)$ & $36(54.54 \%)$ & \\
\hline \multicolumn{4}{|l|}{ Anxiety symptoms ${ }^{\mathrm{a}}$} \\
\hline None & $21(15.32 \%)$ & $15(22.72 \%)$ & $<0.001$ \\
\hline Mild to moderate & $56(40.87 \%)$ & $34(51.51 \%)$ & \\
\hline Severe & $60(43.79 \%)$ & $17(25.75 \%)$ & \\
\hline \multicolumn{4}{|l|}{ Substance abuse } \\
\hline Cannabis & $20(16.25 \%)$ & $9(13.63 \%)$ & 0.26 \\
\hline Cocaine & $8(5.83 \%)$ & I (I.5I\%) & \\
\hline Nonprescribed opiates & $3(2.18 \%)$ & $2(3.03 \%)$ & \\
\hline Nonprescribed benzodiazepines & $7(5.10 \%)$ & $0(0.00 \%)$ & \\
\hline Alcohol & $51(37.22 \%)$ & $20(30.30 \%)$ & 0.79 \\
\hline
\end{tabular}

Note: ${ }^{a}$ Denotes statistical significance.

counter sleeping aids, $14.3 \%$ reported using cannabis, $4.4 \%$ reported using cocaine, $3.4 \%$ admitted to using nonprescribed benzodiazepines, and $2.5 \%$ reported using illicit opiates/heroin. Other variables examined in the survey are listed in Table 1.

Screening for insomnia revealed its overall prevalence to be $67.4 \%$ in our sample. Per the ISI results, 25 participants $(12.3 \%)$ were found to have severe insomnia, 55 participants (27.1\%) moderate insomnia, and 57 participants $(28.1 \%)$ mild insomnia. Screening for RLS revealed a prevalence of $14.3 \%$ in our sample. The severity of insomnia was found to have a significant association with the severity of RLS ( $p=0.04)$ (Table 2).

The mean PHQ score of this sample was found to be $14.13 \pm 7.65$, and the mean GAD score was 11.79 \pm 6.11 . The severity of depressive and anxiety symptomatology was associated with a higher severity of insomnia $(p=0.00)$ (Table 1). Insomnia was found to be associated with suicidal ideation $(p=0.03)$. The use of selective serotonin reuptake inhibitors (SSRIs) $(p=0.02)$ and the use of benzodiazepines $(p=0.02)$ were also found to be associated with the presence

Table 2 Patients with insomnia and RLS per the RLSRS

\begin{tabular}{|c|c|c|c|}
\hline $\begin{array}{l}\text { Insomnia } \\
\text { severity }\end{array}$ & $\begin{array}{l}\text { Patients with } \\
\text { no or mild } \\
\text { RLS (\%) } \\
\mathbf{N}=\mid 73\end{array}$ & $\begin{array}{l}\text { Patients with } \\
\text { moderate-to- } \\
\text { severe RLS (\%) } \\
\mathbf{N}=\mathbf{3 0}\end{array}$ & p-value \\
\hline None & $62(35.8 \%)$ & 4 (I3.3\%) & 0.04 \\
\hline Mild & $5 \mathrm{I}(29.5 \%)$ & $6(20.0 \%)$ & \\
\hline Moderate & 39 (22.5\%) & 16 (53.3\%) & \\
\hline Severe & 21 (12.1\%) & 4 (I3.3\%) & \\
\hline
\end{tabular}

Abbreviations: RLS, restless leg syndrome; RLSRS, restless legs syndrome rating scale. 
of insomnia. Among the participants taking benzodiazepines, $11.4 \%$ had severe insomnia, $18.6 \%$ had moderate insomnia, $24.3 \%$ had mild insomnia, and $45.7 \%$ had no insomnia. There was no significant correlation between benzodiazepine use and insomnia severity.

No significant association was found between the presence of insomnia and the use of antipsychotics $(p=0.50)$, mood stabilizers $(p=0.74)$, selective serotonin-norepinephrine reuptake inhibitors $(p=0.58)$, and tricyclic antidepressants $(p=0.21)$.

No significant association was found between recreational drug use $(p=0.26)$ or alcohol abuse $(p=0.79)$ and the presence or absence of insomnia.

\section{Discussion}

The relationship between insomnia and psychiatric disorders has been relatively well established in the literature. ${ }^{5,18-20}$ By examining the prevalence of insomnia and its associated factors among hospitalized psychiatric patients, the results of this study indicate a strong association between insomnia, RLS, and psychiatric disorders. The prevalence of insomnia among adults is in the range of $9 \%-12 \% \%^{21-23}$ and is more prevalent among women. ${ }^{21,24}$ In our sample, there was no significant difference in the prevalence of insomnia between both sexes. A significant association was found between self-reported sleep time and insomnia in our sample. Most adults in the general population report sleeping 6-7 hours per night. ${ }^{25,26}$ Participants who slept less than 7 hours per night were found to have the highest burden of insomnia $(55.47 \%)$. The association between self-reported sleep time and insomnia in this sample of hospitalized psychiatric patients (Table 1) is consistent with data available in the literature. ${ }^{27-29}$ In our sample, $67.4 \%$ screened positive for insomnia per the ISI. This prevalence exceeds the prevalence of insomnia in previous studies that examined insomnia in psychiatric populations. ${ }^{30}$ The severity of the psychiatric disorders in our sample may have contributed to the high rates of insomnia observed, since our participants were hospitalized patients. The prevalence of insomnia in nonhospitalized psychiatric patients was reported at $43.0 \%$ in some studies, which is significantly higher than insomnia in the general population. ${ }^{21-23,30}$

The diathesis-stress model potentially explain some of our findings. ${ }^{31,32}$ Stress from mental illness may trigger insomnia, and subsequently the stress created by an episode of insomnia can exacerbate the mental health disorder which in turn worsens the insomnia. Up to $90 \%$ of depressed patients have reported sleep disturbances as a symptom of their illness. ${ }^{33,34}$ A recent cross-sectional study from the United States showed that increased insomnia frequency was related to increased depression and anxiety. ${ }^{32,35}$ Suicidal ideation was found to be significantly associated with moderate-to-severe insomnia in this study. This finding is consistent with historical data in the literature and more robust recent data suggestive of a higher risk of suicide among insomniacs. ${ }^{36-38}$ This is of particular concern in an at-risk population such as hospitalized psychiatric patients since the severity of insomnia has been linked to suicidality and a poorer response to antidepressants. ${ }^{39-42}$

Polysomnographic data show that individuals with generalized anxiety disorder and panic disorder have sleep initiation and sleep maintenance difficulties. ${ }^{43,44}$ In a Lebanese study, $10.6 \%$ of young adults were found to have insomnia. ${ }^{45}$ Our study showed that clinically significant anxiety was more frequent in patients suffering from insomnia.

Sleep disorders are common in substance abusers. ${ }^{46}$ In our sample, there was no significant association between substance abuse and insomnia. This finding is likely due to the relatively small number of substance abuse patients in this study $(15.8 \%)$.

In our sample, we detected a clinically significant association between the severity of RLS and insomnia, where $53.3 \%$ of participants with moderate-to-severe RLS were found to have insomnia (Table 2). This finding is consistent with data in the literature that shows that patients with RLS are twice as likely to suffer from insomnia when compared to non-RLS patients ${ }^{47}$ and that in severe RLS insomnia prevalence is around $90 \% .{ }^{48}$ A study by our group showed an association between suicidal ideation and RLS among hospitalized psychiatric patients. ${ }^{49}$ The association between the severity of RLS and insomnia is challenging to interpret due to the bidirectional relationship between both disorders and confounding factors such as the effects of psychotropics on RLS. ${ }^{48}$ SSRIs, which are commonly prescribed for depression and anxiety, have been found to exacerbate RLS ${ }^{50,51}$ and can also affect sleep architecture. ${ }^{52,53}$

Our results showed a significant association between the use of SSRIs and the severity of insomnia. This finding should be interpreted carefully since the sample size is not sufficient to determine a causal relationship between SSRIs and insomnia. However, several SSRIs have been linked to difficulties initiating sleep ${ }^{54}$ and increased sleep fragmentation on polysomnography. ${ }^{55-58}$ Pharmacological studies indicate that almost $40 \%$ of patients treated with SSRIs receive concomitant benzodiazepines for the treatment of insomnia. ${ }^{59}$ 
Interestingly, our data showed that insomnia was significantly associated with the use of benzodiazepines. Benzodiazepines have been studied extensively and have been shown to be beneficial in the short-term treatment of insomnia. ${ }^{60-63}$ This could explain the significant association found in this study between insomnia and the use of benzodiazepines. The severity of insomnia did not correlate significantly with benzodiazepine use. This finding can be attributed to the use of benzodiazepines for treating anxiety disorders among hospitalized psychiatric patients and not necessarily for insomnia. ${ }^{64,65}$ It is also feasible that insomniacs in general stop responding to benzodiazepines over time due to development of tolerance.

This study has several limitations. Since this was a crosssectional study, it precludes the ability to infer causality or temporal effects, or the effects of medications. Questionnaires were used to screen for insomnia, depression, RLS, and anxiety; although sensitive and specific, these surveys cannot diagnose specific disorders. The lack of objective sleep testing and secondary confirmation using a structured psychiatric interview or polysomnography/actigraphy to diagnose insomnia are also a significant limitation. Polysomnographic testing was not feasible due to the severity of psychiatric symptoms in our sample and logistical difficulties. We are planning a follow-up study that will utilize actigraphy to better quantify insomnia and sleep patterns among hospitalized psychiatric patients. The sample size is also a limitation which may have contributed to the lack of association between insomnia, gender, and age. ${ }^{21-24}$ However, it was challenging to recruit patients since many of the patients at our inpatient psychiatry unit were not psychiatrically stable or cognitively intact to consent or participate. In future projects, this limitation can be addressed by conducting multicenter studies. Circadian rhythm disorders and hypersomnia/narcolepsy were not directly addressed in this study. However, these disorders have a much lower prevalence than insomnia; ${ }^{66,67}$ therefore, it would not have been feasible to detect these disorders given our sample size. No significant association was found among psychotic disorders and insomnia, contradicting data in the literature which established an association between psychosis and insomnia. ${ }^{68,69}$ This can be attributed to the relatively small sample size and including all psychotic disorders in one category for data collection purposes. Therefore, subgroup (schizophrenia versus schizoaffective) analysis was not possible. Another limitation is that specific psychotropic medication effects and polypharmacy effects were not controlled for in our study. This was not technically feasible given the diverse and heterogeneous patient population hospitalized at our inpatient psychiatric facility.
Given the high prevalence of insomnia detected in our study and its association with suicidal ideation, it is important to systematically screen hospitalized psychiatric patients for sleep disorders in general and insomnia in particular. Additionally, psychiatric patients may benefit from routine screening for RLS. RLS was found to be quite prevalent in our population and may mimic insomnia. Collaboration with a sleep medicine specialist is recommended in complex sleep disorder cases. Controlling insomnia and any concomitant sleep disorder (such as RLS) will have a positive impact on hospitalized psychiatric patients. It is feasible and cost-effective to include routine screening for sleep disorders when evaluating psychiatric patients. If the patient is unable to provide a sleep history, a significant other or family member may be queried for a sleep history. Increasing awareness among psychiatric nurses, residents, and psychiatrists regarding the deleterious effects of sleep disorders on mental illness is advised. It is essential not to normalize sleep disturbances in psychiatric patients as an inevitable consequence of mental illness or psychotropic medications.

\section{Acknowledgment}

We acknowledge the American University of Beirut Medical Center inpatient psychiatric unit for facilitating the recruitment process.

\section{Author contribution}

FT, JA, and FK worked on the study conceptualization and design. FT, JA, HG, and ASA worked on recruiting participants and performed data analysis. All authors critically revised the manuscript and approved of the final version.

\section{Disclosure}

The authors report no conflicts of interest in this work.

\section{References}

1. Cinosi E, Di Iorio G, Acciavatti T, et al. Sleep disturbances in eating disorders: a review. La Clinica terapeutica. 2011;162(6):e195-e202.

2. Abe Y, Suganuma T, Ishii M, et al. Association of genetic, psychological and behavioral factors with sleep bruxism in a Japanese population. J Sleep Res. 2012;21(3):289-296.

3. Stranges S, Tigbe W, Gómez-Olivé FX, Thorogood M, Kandala NB. Sleep problems: an emerging global epidemic? Findings from the INDEPTH WHO-SAGE study among more than 40,000 older adults from 8 countries across Africa and Asia. Sleep. 2012;35(8):1173-1181.

4. Etain B, Dumaine A, Bellivier F, et al. Genetic and functional abnormalities of the melatonin biosynthesis pathway in patients with bipolar disorder. Hum Mol Genet. 2012;21(18):4030-4037.

5. Sateia MJ. Update on sleep and psychiatric disorders. Chest. 2009;135(5): 1370-1379.

6. Sivertsen B, Posserud MB, Gillberg C, Lundervold AJ, Hysing M. Sleep problems in children with autism spectrum problems: a longitudinal population-based study. Autism. 2012;16(2):139-150. 
7. Batterham PJ, Glozier N, Christensen H. Sleep disturbance, personality and the onset of depression and anxiety: prospective cohort study. Aust N Z J Psychiatry. 2012;46(11):1089-1098.

8. Waters F, Faulkner D, Naik N, Rock D. Effects of polypharmacy on sleep in psychiatric inpatients. Schizophr Res. 2012;139(1):225-228.

9. Ghandour LA, El Sayed DS, Martins SS. Prevalence and patterns of commonly abused psychoactive prescription drugs in a sample of university students from Lebanon: an opportunity for cross-cultural comparisons. Drug Alcohol Depend. 2012;121(1):110-117.

10. Calem M, Bisla J, Begum A, et al. Increased prevalence of insomnia and changes in hypnotics use in England over 15 years: analysis of the 1993, 2000, and 2007 National Psychiatric Morbidity Surveys. Sleep. 2012;35(3):377-384.

11. Spitzer RL, Kroenke K, Williams JB. Validation and utility of a selfreport version of PRIME-MD: the PHQ primary care study. Primary Care Evaluation of Mental Disorders. Patient Health Questionnaire. JAMA. 1999;282(18):1737-1744.

12. Sawaya H, Atoui M, Hamadeh A, Zeinoun P, Nahas Z. Adaptation and initial validation of the Patient Health Questionnaire-9 (PHQ-9) and the Generalized Anxiety Disorder-7 Questionnaire (GAD-7) in an Arabic speaking Lebanese psychiatric outpatient sample. Psychiatry Res. 2016;239:245-252.

13. Spitzer RL, Kroenke K, Williams JB, Löwe B. A brief measure for assessing generalized anxiety disorder: the GAD-7. Arch Intern Med. 2006;166(10):1092-1097.

14. Bastien CH, Vallières A, Morin CM. Validation of the Insomnia Severity Index as an outcome measure for insomnia research. Sleep Med. 2001;2(4):297-307.

15. Ahmed AE. Validation of Arabic versions of three sleep surveys. Qatar Med J. 2014;2014(2):130-136.

16. Group IRLSS. Validation of the International Restless Legs Syndrome Study Group rating scale for restless legs syndrome. Sleep Med. 2003;4(2):121-132.

17. Abetz L, Vallow SM, Kirsch J, Allen RP, Washburn T, Earley CJ. Validation of the restless legs syndrome quality of life questionnaire. Value Health. 2005;8(2):157-167.

18. Ohayon MM. Prevalence of DSM-IV diagnostic criteria of insomnia: distinguishing insomnia related to mental disorders from sleep disorders. J Psychiatr Res. 1997;31(3):333-346.

19. Taylor DJ, Lichstein KL, Durrence HH. Insomnia as a health risk factor. Behav Sleep Med. 2003;1(4):227-247.

20. Franzen PL, Buysse DJ. Sleep in psychiatric disorders. In: Sudhansu C, editor. Sleep Disorders Medicine. New York, NY: Springer; 2017 : 977-996.

21. Buysse DJ, Angst J, Gamma A, Ajdacic V, Eich D, Rössler W. Prevalence, course, and comorbidity of insomnia and depression in young adults. Sleep. 2008;31(4):473-480.

22. Ford DE, Kamerow DB. Epidemiologic study of sleep disturbances and psychiatric disorders: an opportunity for prevention? JAMA. 1989;262(11):1479-1484.

23. Mellinger GD, Balter MB, Uhlenhuth EH. Insomnia and its treatment: prevalence and correlates. Arch Gen Psychiatry. 1985;42(3):225-232.

24. Roehrs T, Zorick FJ, Roth T. Transient and short-term insomnias. In: Kryger MH, Roth T, Dement WC, editors. Principles and Practice of Sleep Medicine. Philadelphia, PA: WB Saunders; 2000:624-632.

25. Jean-Louis G, Kripke DF, Ancoli-Israel S, Klauber MR, Sepulveda RS. Sleep duration, illumination, and activity patterns in a population sample: effects of gender and ethnicity. Biol Psychiatry. 2000;47(10): 921-927.

26. Spiegel K, Tasali E, Penev P, Van Cauter E. Brief communication: sleep curtailment in healthy young men is associated with decreased leptin levels, elevated ghrelin levels, and increased hunger and appetite. Ann Intern Med. 2004;141(11):846-850.

27. Wingard DL, Berkman LF. Mortality risk associated with sleeping patterns among adults. Sleep. 1983;6(2):102-107.

28. Kripke DF, Simons RN, Garfinkel L, Hammond EC. Short and long sleep and sleeping pills: is increased mortality associated? Arch Gen Psychiatry. 1979;36(1):103-116.
29. Carskadon MA, Dement WC, Mitler M, Guilleminault C, Zarcone VP, Spiegel R. Self-reports versus sleep laboratory findings in 122 drugfree subjects with complaints of chronic insomnia. Am J Psychiatry. 1976;133(12):1382-1388

30. Johnson EO, Roth T, Breslau N. The association of insomnia with anxiety disorders and depression: exploration of the direction of risk. J Psychiatr Res. 2006;40(8):700-708.

31. Monroe SM, Simons AD. Diathesis-stress theories in the context of life stress research: implications for the depressive disorders. Psychol Bull. 1991;110(3):406-425.

32. Taylor DJ, Lichstein KL, Durrence HH, Reidel BW, Bush AJ. Epidemiology of insomnia, depression, and anxiety. Sleep. 2005;28(11): 1457-1464.

33. Palagini L, Baglioni C, Ciapparelli A, Gemignani A, Riemann D. REM sleep dysregulation in depression: state of the art. Sleep Med Rev. 2013; 17(5):377-390

34. Kupfer D. Application of EEG sleep for the differential diagnosis and treatment of affective disorders. Pharmacopsychiatry. 1978; 11(01):17-26

35. Jindal RD, Thase ME. Treatment of insomnia associated with clinical depression. Sleep Med Rev. 2004;8(1):19-30.

36. Fujino Y, Mizoue T, Tokui N, Yoshimura T. Prospective cohort study of stress, life satisfaction, self-rated health, insomnia, and suicide death in Japan. Suicide Life Threat Behav. 2005;35(2):227-237.

37. Woznica AA, Carney CE, Kuo JR, Moss TG. The insomnia and suicide link: toward an enhanced understanding of this relationship. Sleep Med Rev. 2015;22:37-46.

38. Pronger CE. Insomnia and suicide. Lancet. 1914;184(4763):1356-1359.

39. Ağargün MY, Kara H, Solmaz M. Sleep disturbances and suicidal behavior in patients with major depression. J Clin Psychiatry. 1997;58(6): 249-251.

40. Fawcett J, Scheftner WA, Fogg L, Clark DC, Young MA. Time-related predictors of suicide in major affective disorder. Am J Psychiatry. 1990;147(9):1189-1194.

41. Reynolds CF, Frank E, Houck PR, et al. Which elderly patients with remitted depression remain well with continued interpersonal psychotherapy after discontinuation of antidepressant medication? Am J Psychiatry. 1997;154(7):958-962.

42. Thase ME, Simons AD, Reynolds CF. Abnormal electroencephalographic sleep profiles in major depression: association with response to cognitive behavior therapy. Arch Gen Psychiatry. 1996;53(2):99-108.

43. Reynolds CF, Shaw DH, Newton TF, Coble PA, Kupfer DJ. EEG sleep in outpatients with generalized anxiety: a preliminary comparison with depressed outpatients. Psychiatry Res. 1983;8(2):81-89.

44. Fuller KH, Waters WF, Binks PG, Anderson T. Generalized anxiety and sleep architecture: a polysomnographic investigation. Sleep. 1997; 20(5):370-376

45. Choueiry N, Salamoun T, Jabbour H, El Osta N, Hajj A, Khabbaz LR. Insomnia and relationship with anxiety in university students: a crosssectional designed study. PLoS One. 2016;11(2):e0149643.

46. Mahfoud Y, Talih F, Streem D, Budur K. Sleep disorders in substance abusers: how common are they? Psychiatry (Edgmont). 2009;6(9): $38-42$.

47. Mucsi I, Molnar MZ, Ambrus C, et al. Restless legs syndrome, insomnia and quality of life in patients on maintenance dialysis. Nephrol Dial Transplant. 2005;20(3):571-577.

48. Montplaisir J, Boucher S, Poirier G, Lavigne G, Lapierre O, Lespérance P. Clinical, polysomnographic, and genetic characteristics of restless legs syndrome: a study of 133 patients diagnosed with new standard criteria. Mov Disord. 1997;12(1):61-65.

49. Talih F, Ajaltouni J, Kobeissy F. Restless leg syndrome in hospitalized psychiatric patients in Lebanon: a pilot study. Neuropsychiatr Dis Treat. 2016;12:2581-2586.

50. Hargrave R, Beckley DJ. Restless leg syndrome exacerbated by sertraline. Psychosomatics. 1998;39(2):177-178.

51. Rottach KG, Schaner BM, Kirch MH, et al. Restless legs syndrome as side effect of second generation antidepressants. J Psychiatric Res. 2008;43(1):70-75. 
52. Ohayon MM, Caulet M. Psychotropic medication and insomnia complaints in two epidemiological studies. Can J Psychiatry. 1996;41(7): 457-464.

53. Asnis GM, Chakraburtty A, DuBoff EA, et al. Zolpidem for persistent insomnia in SSRI-treated depressed patients. J Clin Psychiatry. 1999;60(10):668-676.

54. Jindal RD, Friedman ES, Berman SR, Fasiczka AL, Howland RH, Thase ME. Effects of sertraline on sleep architecture in patients with depression. J Clin Psychopharmacol. 2003;23(6):540-548.

55. Rush AJ, Armitage R, Gillin JC, et al. Comparative effects of nefazodone and fluoxetine on sleep in outpatients with major depressive disorder. Biol Psychiatry. 1998;44(1):3-14.

56. Shipley JE, Kupfer DJ, Dealy RS, et al. Differential effects of amitriptyline and of zimelidine on the sleep electroencephalogram of depressed patients. Clin Pharmacol Ther. 1984;36(2):251-259.

57. Staner L, Kerkhofs M, Detroux D, Leyman S, Linkowski P, Mendlewicz J. Acute, subchronic and withdrawal sleep EEG changes during treatment with paroxetine and amitriptyline: a double-blind randomized trial in major depression. Sleep. 1995;18(6):470-477.

58. Hicks JA, Argyropoulos SV, Rich AS, et al. Randomised controlled study of sleep after nefazodone or paroxetine treatment in out-patients with depression. Br J Psychiatry. 2002;180(6):528-535.

59. Grunze H, Kasper S, Goodwin G, et al. World Federation of Societies of Biological Psychiatry (WFSBP) guidelines for biological treatment of bipolar disorders, part I: treatment of bipolar depression. World $J$ Biol Psychiatry. 2002;3(3):115-124.

60. Dominguez RA, Jacobson AF, Goldstein BJ, Steinbook RM. Comparison of triazolam and placebo in the treatment of insomnia in depressed patients. Curr Ther Res. 1984;36(5):856-865.
61. Cohn JB. Triazolam treatment of insomnia in depressed patients taking tricyclics. J Clin Psychiatry. 1983;44(1):401-406.

62. Nolen WA, Haffmans PJ, Bouvy PF, Duivenvoorden HJ. Hypnotics as concurrent medication in depression: a placebo-controlled, double-blind comparison of flunitrazepam and lormetazepam in patients with major depression, treated with a (tri) cyclic antidepressant. $J$ Affect Disord. 1993;28(3):179-188.

63. Scharf M, Hirschowitz J, Zemlan F, Lichstein M, Woods M. Comparative effects of limbitrol and amitriptyline on sleep efficiency and architecture. J Clin Psychiatry. 1986;47(12):587-591.

64. Starcevic V. The reappraisal of benzodiazepines in the treatment of anxiety and related disorders. Expert Rev Neurother. 2014;14(11): $1275-1286$

65. Stein MB, Craske MG. Treating anxiety in 2017: optimizing care to improve outcomes. JAMA. 2017;318(3):235-236.

66. Schenck CH, Bundlie SR, Ettinger MG, Mahowald MW. Chronic behavioral disorders of human REM sleep: a new category of parasomnia. Sleep. 1986;9(2):293-308.

67. Longstreth W Jr, Koepsell TD, Ton TG, Hendrickson AF, Van Belle G. The epidemiology of narcolepsy. Sleep. 2007;30(1):13-26.

68. Li SX, Lam SP, Zhang J, et al. Sleep disturbances and suicide risk in an 8-year longitudinal study of schizophrenia-spectrum disorders. Sleep. 2016;39(6):1275-1282.

69. Mulligan LD, Haddock G, Emsley R, Neil ST, Kyle SD. High resolution examination of the role of sleep disturbance in predicting functioning and psychotic symptoms in schizophrenia: A novel experience sampling study. J Abnormal Psychol. 2016;125(6):788.
Neuropsychiatric Disease and Treatment

\section{Publish your work in this journal}

Neuropsychiatric Disease and Treatment is an international, peerreviewed journal of clinical therapeutics and pharmacology focusing on concise rapid reporting of clinical or pre-clinical studies on a range of neuropsychiatric and neurological disorders. This journal is indexed on PubMed Central, the 'PsycINFO' database and CAS,

\section{Dovepress}

and is the official journal of The International Neuropsychiatric Association (INA). The manuscript management system is completely online and includes a very quick and fair peer-review system, which is all easy to use. Visit http://www.dovepress.com/testimonials.php to read real quotes from published authors. 